\title{
Psychological Impact Assessment in Patients with Noncommunicable Diseases during COVID-19 Pandemic through Validated Fear of COVID-19 scale: A Cross-Sectional Online Survey
} \author{
Shanmukha P. Konduru ${ }^{1}$ \\ ${ }^{1}$ Drug Standardisation Unit (Homoeopathy), Central Council for \\ Research in Homoeopathy, Ministry of Ayush, Govt. of India, \\ Hyderabad, Telangana, India \\ 2 Department of Clinical Pharmacy and Pharmacology, Ibn sina \\ National College for Medical Studies, Jeddah, Saudi Arabia \\ ${ }^{3}$ Department of Physiology, Jeeyar Integrative Medical Services \\ Homoeopathic Medical College and Hospital, Hyderabad, \\ Telangana, India \\ J Health Allied Sci ${ }^{\mathrm{NU}}$ 2022;12:392-397.
}

Hima B. Ponnam ${ }^{10}$ Butchi R. Akondi ${ }^{2}$ Santosh K. Jagadabhi ${ }^{3}$ Divya T. Koppula1잉

\author{
Address for correspondence Dr Hima B. Ponnam, Scientist III, Drug \\ Standardisation Unit (Homoeopathy), Central Council for Research in \\ Homoeopathy, Ministry of Ayush, Govt. of India, Hyderabad, \\ Telangana - 500007, India (e-mail: drdewdrop@gmail.com).
}

\author{
Abstract \\ Keywords \\ - COVID-19 pandemic \\ - cross-sectional survey \\ - FCV-19S \\ - fear of COVID-19 \\ scale \\ - India \\ - noncommunicable \\ diseases \\ - NCD
}

Background The novel coronavirus disease 2019 (COVID-19) pandemic has created immense panic globally with its advent in December 2019 and now showing readvent with its camouflage of different dangerous mutant strains. Its psychological repercussions on the community are very disastrous and immeasurable. At this juncture, the most vulnerable group are the patients of Noncommunicable diseases (NCDs) who are the most sufferers due to the impact caused by the anxiety and fear of COVID-19 apart from its high rate of infectivity. In this context, an online survey to assess the levels of anxiety and fear of COVID-19 in patients with lifestyle diseases has been taken up. Methods This was an online cross-sectional survey using the Fear of COVID-19 Scale (FCV-19S) to assess the levels of anxiety and fear in patients with NCDs. The survey was made available for both genders and an age group of 30 years and above in India. Results and Discussion A total of 627 participants participated in this online survey. The Indian residents with NCDS (Noncommunicable diseases) were found to suffer from significantly increased levels of anxiety and fear of COVID-19 and almost $60.4 \%$ of the participants were found to acquire these lifestyle diseases as diabetes and hypertension during this recent COVID-19 times.

Conclusion This survey shows the real-time psychological impact of COVID-19 which has a disastrous effect upon the community especially on the patients with NCDs who are the most vulnerable group. The study findings corroborate with the recent studies conducted on NCDs. published online January 18, 2022
DOI https://doi.org/ $10.1055 / \mathrm{s}-0041-1741431$ ISSN 2582-4287.

\footnotetext{
(c) 2022. Nitte (Deemed to be University). All rights reserved. This is an open access article published by Thieme under the terms of the Creative Commons Attribution-NonDerivative-NonCommercial-License, permitting copying and reproduction so long as the original work is given appropriate credit. Contents may not be used for commercial purposes, or adapted, remixed, transformed or built upon. (https://creativecommons.org/ licenses/by-nc-nd/4.0/) Thieme Medical and Scientific Publishers Pvt. Ltd., A-12, 2nd Floor, Sector 2, Noida-201301 UP, India
} 


\section{Introduction}

The noncommunicable disease (NCD) burden shows a steep rise during this novel coronavirus disease 2019 (COVID-19) pandemic. The forced sedentary life imposed due to the implementation of the lockdowns, pandemic preventive restrictions, anxiety, and fear components of contracting COVID-19 has become the common triggering factors for the rise of new NCD cases and also worsening of the already suffering patients. After combating the last years (2020) pandemic situation, the outpatient departments of many physicians (government and private) experienced a surge of NCD cases. The year 2020 totally turned our heads toward the COVID-19 pandemic and made us blind toward the hydraheaded monster of NCDs. ${ }^{1,2}$ And the current second wave is really disastrous throwing the patients suffering with NCDs into uncertainty once again leading to a large chaos not only in India but world-wide. The rapid assessment conducted by the World Health Organization (WHO) in 2020 showed that there is a steep rise in NCDs and worsening of NCD cases leading to increased emergency deaths due to the total disruption of the health care systems on account of fast spread of COVID-19 infections. Even the funds allocated to NCDs by governments are reallocated to combat COVID-19 emergencies and especially in South-East Asian Regions (SEAR) approximately 51 to $75 \%$ funds have been reallocated which led to worst scenario for patients of NCDs. ${ }^{3}$

India is the most thickly populated country among the SEAR and constitutes of 1.3 billion population. NCDs account almost 5.87 million (60\%) of all deaths in India. The major prevalent NCDs are diabetes, cardiovascular diseases, cancer, and chronic respiratory diseases. The negligence of NCDs due to the COVID-19 crisis during the last 1 year may lead to the advent of an unexpected monstrous hydraheaded NCD pandemic in the near future which would pose a major threat for any health care system to handle. ${ }^{4}$ This study is an attempt to evaluate the levels of fear and anxiety suffered by the patients of NCDs and to report the occurrences of new NCD cases during the last 1.5 years of COVID-19 times which is still continuing with its aura of new strains as a second wave in India.

\section{Materials and Methods}

\section{Duration of Survey}

This was an online cross-sectional survey using the Fear of COVID-19 Scale (FCV-19S) to assess the levels of anxiety and fear in patients with NCDs diseases. The survey was made available online from February 7, 2021, to February 27, 2021 ( 3 weeks). As the second wave of COVID-19 is increasing rapidly, we decided to take up this community-based crosssectional survey online.

\section{Sample}

The survey was made available for both genders and an age group of 30 years and above. The participants for this study were recruited through online social media platforms as "WhatsApp, Facebook, and Twitter." An online snowball research sampling technique was used to recruit as many participants as possible. Research fellows and medical practitioners disseminated this survey on social media groups and encouraged its publication to other groups. Participation was on a voluntary basis. The minimal sample size of this study was based on a power calculation done prior to the survey. It was decided to recruit at least 200 participants, as this would give a sufficient statistical power $(0.80)$ to depict small correlations. The survey was unveiled with an open motto for a large sample size to strengthen the results. The study was initially planned for 4 weeks but closed earlier, as preferred sample size was attained by 3 weeks.

\section{Measures}

The survey questionnaire consisted of two parts. First part is the demographic data and the second part is the FCV-19S. Demographic variables included age, gender, education, occupation, current place of residence (any part of India), type of NCD suffering, duration of the suffering, and family history of NCDs. The FCV-19S questionnaire has been developed and initially validated by a team of experts (Ahorsu et al). ${ }^{5}$ Later, the scale was validated with translations into various other languages. ${ }^{6-8}$ The FCV-19S consists of seven questions evaluating the anxiety and fear levels of the patients with NCDs. The internal consistency of the FCV$19 \mathrm{~S}$ for the sample was calculated using Cronbach's $\alpha$ coefficient. It was decided to make random calls among the enrolled participants to evaluate the health consequences and challenges faced by them during this COVID-19 challenging times. The institutional ethical committee approval has been sought prior to the administration of the survey.

\section{Statistical Analysis}

The study results were analyzed using SPSS version 25 . Frequency analysis was done for all the nominal scale and ordinal scale sociodemographic variables. The data are presented in mean \pm standard deviation (SD) for numeric variables, frequency, or percentages for nominal and ordinal scale variables. Nonparametric Chi-square test was used to test the frequency of nominal and ordinal scale variables. Also, $t$-tests were used to compare the total anxiety score for the two demographic variables and contained two levels. One-way analysis of variance (ANOVA) was used to compare the total anxiety score for demographic variables having more than two levels. Further, multiple regression analysis was performed to investigate the potential predictors for anxiety score of respondents during the COVID-19 outbreak. Spearman's rank correlation was used to study the relationship between participants age and the levels of anxiety.

\section{Results}

A total of 627 participants provided consent to participate; however, 498 respondents out of them completed the survey (completion rate: $79.4 \%$ ) representing five different states of India. The Cronbach's $\alpha$ coefficient of the knowledge questionnaire was 0.86 in the sample indicating acceptable internal consistency. The majority responses of the 
Table 1 Fear of COVID-19 questionnaire with responses of the participants

\begin{tabular}{|l|l|l|l|l|l|l|l|}
\hline Variables & $\begin{array}{l}\text { Strongly } \\
\text { disagree (\%) }\end{array}$ & $\begin{array}{l}\text { Disagree } \\
(\%)\end{array}$ & $\begin{array}{l}\text { Neutral } \\
(\%)\end{array}$ & Agree (\%) & $\begin{array}{l}\text { Strongly } \\
\text { agree (\%) }\end{array}$ & $x^{2}$ & $p$-Value \\
\hline I am most afraid of corona & $7(1.4)$ & $22(4.4)$ & $38(7.6)$ & $311(62.4)$ & $120(24.1)$ & 637.522 & 0.000 \\
\hline $\begin{array}{l}\text { It makes me uncomfortable to } \\
\text { think about corona }\end{array}$ & $11(2.2)$ & $26(5.2)$ & $48(9.6)$ & $307(61.6)$ & $106(21.3)$ & 592.221 & 0.000 \\
\hline $\begin{array}{l}\text { My hands become clammy } \\
\text { when I think about corona }\end{array}$ & $15(3)$ & $46(9.2)$ & $68(13.7)$ & $276(55.4)$ & $93(18.7)$ & 423.586 & 0.000 \\
\hline $\begin{array}{l}\text { I am afraid of losing my life } \\
\text { because of corona }\end{array}$ & $16(3.2)$ & $48(9.6)$ & $30(6)$ & $227(45.6)$ & $177(35.5)$ & 368.647 & 0.000 \\
\hline $\begin{array}{l}\text { When I watch news and } \\
\text { stories about corona on social } \\
\text { media, I become nervous or } \\
\text { anxious }\end{array}$ & $8(1.6)$ & $39(7.8)$ & $126(25.3)$ & $219(44)$ & $106(21.3)$ & 271.659 & 0.000 \\
\hline $\begin{array}{l}\text { I cannot sleep because I'm } \\
\text { worrying about getting } \\
\text { corona }\end{array}$ & $21(4.2)$ & $51(10.2)$ & $106(21.3)$ & $220(44.2)$ & $100(20.1)$ & 231.699 & 0.000 \\
\hline $\begin{array}{l}\text { My heart races or palpitates } \\
\text { when I think about getting } \\
\text { corona }\end{array}$ & $16(3.2)$ & $39(7.8)$ & $109(21.9)$ & $221(44.4)$ & $113(22.7)$ & 257.703 & 0.000 \\
\hline
\end{tabular}

Abbreviation: COVID-19, novel coronavirus disease 2019.

participants were found to be "toward agree" and "strongly agree" as per the options given in the questionnaire as shown in the - Table 1. The maximum responses of the participants showed an increased level of anxiety and fear toward COVID19 as shown in - Fig. 1. There was a high correlation between items $3,5,6$, and 7 , suggesting that these items could indicate the physiological responses to fear, and a high correlation between items 1,2 , and 4 , suggesting these items could represent the emotional responses to fear. Our survey shows a significantly higher level of fear in patients with NCDs.

The sociodemographic characteristics of the participants are as given in - Table $\mathbf{2}$. The male and female ratio is almost equal. Almost $79.3 \%$ of the participants are from the state of Telangana.

Among the participants, the commonly suffering NCD is the hypertension (74.3\%), next is diabetes mellitus (27.5\%), and the rest are stroke, cardiovascular diseases, and cancer. And almost $64.4 \%$ of the participants suffered NCDs since the

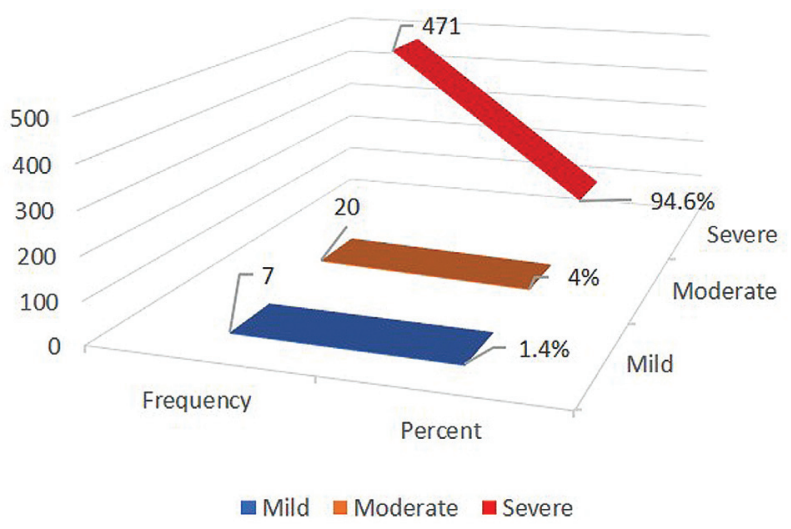

Fig. 1 The level of anxiety and fear of COVID-19 among participants. COVID-19, novel coronavirus disease 2019. past 2 years depicted by the duration of disease as shown in -Table 3. The family history of NCDs presented by the participants is given in the - Table 4. The ANOVA analysis between demographic variables and FCV-19S questions and after multiple regression analysis is listed in - Table 5, the results show that except age, all other sociodemographic variables significantly influences the anxiety levels of the participants. Also $50 \%$ of the responded participants were made random phone calls to understand the health consequences, these patients suffered during restrictions of COVID-19 times. Almost $40 \%$ of the participants responded to the calls and reported fluctuations in blood sugar levels, blood pressure, and few even experienced heart problems.

\section{Discussion}

The NCD patients are the most vulnerable and much suffered group during COVID-19 times. The anxiety and fear component transformed the already suffering NCD cases to a worse state and added up new cases of NCD to the existing account. In spite of all the national preventive programs in vogue by the government, the NCDs are on steep rise in the last 1 year due to the prevalence of COVID-19 infectious disease. The existing risk factors are out of control during the COVID-19 times as sedentary habit, disrupted eating patterns, and special attention to the morbid fear and anxiety added up to worsening of NCDs. ${ }^{3}$

The presence of COVID-19 had a tremendous psychological impact among patients with NCDs, including fear and anxiety, which have worsened their health status. In the current study, the FCV-19S was used to assess the response to fear within NCD patients. There was a high correlation between items $3,5,6$, and 7 , suggesting these items could indicate the physiological responses to fear, and a high correlation between items 1,2 , and 4 , suggesting these items 
Table 2 Sociodemographic characteristics of the participants

\begin{tabular}{|c|c|c|c|}
\hline \multicolumn{2}{|c|}{ Sociographic characteristics } & \multirow{2}{*}{$\begin{array}{l}\text { Frequency } \\
234\end{array}$} & \multirow{2}{*}{$\begin{array}{l}\text { Percentage } \\
47.0\end{array}$} \\
\hline Gender & Male & & \\
\hline & Female & 264 & 53.0 \\
\hline \multirow[t]{4}{*}{ Education } & Below 10th & 63 & 12.7 \\
\hline & Intermediate & 151 & 30.3 \\
\hline & Graduate & 157 & 31.5 \\
\hline & Post graduate and above & 127 & 25.5 \\
\hline \multirow[t]{7}{*}{ Occupation } & Working at govt. sector & 164 & 32.9 \\
\hline & Working at private sector & 27 & 5.4 \\
\hline & Home maker & 148 & 29.7 \\
\hline & Business & 60 & 12.0 \\
\hline & Daily wages and farmer & 23 & 4.6 \\
\hline & Self employed & 48 & 9.6 \\
\hline & Retired & 28 & 5.6 \\
\hline \multirow[t]{5}{*}{ Presently residing state } & Telangana & 395 & 79.3 \\
\hline & Maharashtra & 19 & 3.8 \\
\hline & Karnataka & 4 & 0.8 \\
\hline & Rajasthan & 3 & 0.6 \\
\hline & Andhra Pradesh & 77 & 15.5 \\
\hline
\end{tabular}

Table 3 Type of noncommunicable diseases possessed by the participants with duration

\begin{tabular}{|c|c|c|c|c|c|}
\hline History of diseases & Responses & Frequency & Percentage & $x^{2}$ & p-Value \\
\hline \multirow[t]{2}{*}{ Cancer } & No & 491 & 98.6 & \multirow[t]{2}{*}{470.394} & \multirow[t]{2}{*}{0.000} \\
\hline & Yes & 7 & 1.4 & & \\
\hline \multirow[t]{2}{*}{ Cardiovascular diseases } & No & 472 & 94.8 & \multirow[t]{2}{*}{399.430} & \multirow[t]{2}{*}{0.000} \\
\hline & Yes & 26 & 5.2 & & \\
\hline \multirow[t]{2}{*}{ Diabetes } & No & 361 & 72.5 & \multirow[t]{2}{*}{100.755} & \multirow[t]{2}{*}{0.000} \\
\hline & Yes & 137 & 27.5 & & \\
\hline \multirow[t]{2}{*}{ COPD } & No & 466 & 93.6 & \multirow[t]{2}{*}{378.225} & \multirow[t]{2}{*}{0.000} \\
\hline & Yes & 32 & 6.4 & & \\
\hline \multirow[t]{2}{*}{ Stroke } & No & 488 & 98.0 & \multirow[t]{2}{*}{458.803} & \multirow[t]{2}{*}{0.000} \\
\hline & Yes & 10 & 2.0 & & \\
\hline \multirow[t]{2}{*}{ Hypertension } & No & 128 & 25.7 & \multirow[t]{2}{*}{117.598} & \multirow[t]{2}{*}{0.000} \\
\hline & Yes & 370 & 74.3 & & \\
\hline \multirow[t]{4}{*}{ Duration of illness } & $<1$ year & 51 & 10.2 & \multirow[t]{4}{*}{209.679} & \multirow[t]{4}{*}{0.000} \\
\hline & $1-2$ years & 255 & 51.2 & & \\
\hline & $2-5$ years & 128 & 25.7 & & \\
\hline & $5-10$ years & 64 & 12.9 & & \\
\hline
\end{tabular}

Abbreviation: COPD, chronic obstructive pulmonary disease.

could represent the emotional responses to fear. Our survey shows a significantly higher level of fear in NCD patients.

Significant findings found in the study are that the higher the education, the higher the levels of fear of COVID-19. It depicts that higher the people are educated, they possess indepth understanding of the consequences of COVID-19 and hence the fear component also would be higher. The government employees and home makers possess the higher levels of fear as it stands true confirming that these people are assumed to have most updated news of COVID-19 (government employees due to direct access to updated information and home makers watching news channels at home). 
Table 4 Family history of NCDs among participants

\begin{tabular}{|c|c|c|c|c|c|}
\hline Family history of diseases & Yes/no & Frequency & Percentage & $x^{2}$ & $p$-Value \\
\hline \multirow[t]{2}{*}{ Cancer } & No & 487 & 97.8 & \multirow[t]{2}{*}{454.972} & \multirow[t]{2}{*}{0.000} \\
\hline & Yes & 11 & 2.2 & & \\
\hline \multirow[t]{2}{*}{ Cardiovascular diseases } & No & 462 & 92.8 & \multirow[t]{2}{*}{364.410} & \multirow[t]{2}{*}{0.000} \\
\hline & Yes & 36 & 7.2 & & \\
\hline \multirow[t]{2}{*}{ Diabetes } & No & 393 & 78.9 & \multirow[t]{2}{*}{166.554} & \multirow[t]{2}{*}{0.000} \\
\hline & Yes & 105 & 21.1 & & \\
\hline \multirow[t]{2}{*}{ COPD } & No & 495 & 99.4 & \multirow[t]{2}{*}{486.072} & \multirow[t]{2}{*}{0.000} \\
\hline & Yes & 3 & .6 & & \\
\hline \multirow[t]{2}{*}{ Stroke } & No & 472 & 94.8 & \multirow[t]{2}{*}{399.430} & \multirow[t]{2}{*}{0.000} \\
\hline & Yes & 26 & 5.2 & & \\
\hline \multirow[t]{2}{*}{ Hypertension } & No & 416 & 83.5 & \multirow[t]{2}{*}{224.008} & \multirow[t]{2}{*}{0.000} \\
\hline & Yes & 82 & 16.5 & & \\
\hline
\end{tabular}

Abbreviations: COPD, chronic obstructive pulmonary disease; NCD, noncommunicable diseases.

Table 5 Multiple regression on sociodemographic variables (age, gender, education, and occupation) and anxiety score of respondents

\begin{tabular}{|c|c|c|c|c|c|c|c|c|}
\hline \multirow[t]{2}{*}{ Anxiety } & \multirow[t]{2}{*}{$\begin{array}{l}\text { Unstandardized } \\
\text { coefficients }\end{array}$} & \multirow[t]{2}{*}{$\begin{array}{l}\text { Standardized } \\
\text { coefficients }\end{array}$} & \multirow[t]{2}{*}{$t$-Value } & \multirow[t]{2}{*}{$p$-Value } & \multicolumn{2}{|c|}{$\begin{array}{l}95.0 \% \text { confidence } \\
\text { interval for B }\end{array}$} & \multirow[t]{2}{*}{$R^{2}$} & \multirow[t]{2}{*}{ Adjusted $R^{2}$} \\
\hline & & & & & $\begin{array}{l}\text { Lower } \\
\text { bound }\end{array}$ & $\begin{array}{l}\text { Upper } \\
\text { bound }\end{array}$ & & \\
\hline Model (constant) & 22.317 & & 13.683 & 0.000 & 19.112 & 25.522 & 0.068 & 0.058 \\
\hline Age & 0.038 & 0.087 & 1.938 & 0.053 & -0.001 & 0.076 & & \\
\hline Gender & 1.532 & 0.134 & 2.978 & 0.003 & 0.521 & 2.543 & & \\
\hline Education & 0.829 & 0.143 & 3.158 & 0.002 & 0.313 & 1.344 & & \\
\hline $\begin{array}{l}\text { Occupation, } \\
\text { specify job } \\
\text { description }\end{array}$ & -0.285 & -0.093 & -2.035 & 0.042 & -0.560 & -0.010 & & \\
\hline $\begin{array}{l}\text { Presently } \\
\text { residing state }\end{array}$ & -0.543 & -0.139 & -3.179 & 0.002 & -0.878 & -0.207 & & \\
\hline
\end{tabular}

The duration of NCDs and the family history of NCDs among the participants when analyzed, it was found that even without a family history of NCDs, $60.4 \%$ people were diagnosed with NCDs newly within the last 1.5 years. The most attributed NCDs are hypertension and diabetes where already established studies are available which opines that stress plays a major role of risk in attaining NCDs. The random sample personal interviews taken up through telephonic calls to the $50 \%$ of the responded participants confirmed the worsened health consequences due to their fluctuating blood sugar levels, blood pressure levels, and various heart problems. The fear component thus played a significant role in the disruption of health in patients with NCDs. As per WHO report, NCD patients contracting COVID19 accounted to $21.9 \%$ of deaths globally. ${ }^{9}$

As the second wave of COVID-19 is already in progress in India, it is the prime time to take utmost care to prevent any disruption/denial of the need-based health services to the patients of NCDs. The health care system should be ready to take up challenges through tele-medicine ${ }^{10}$ facilities and online consultations to replenish the general health care system in a safe and secure way in this difficult COVID-19 times. Also, there is need for online community-based health education programs to spread the relevant emergency medical information. ${ }^{11}$ These need to be planned by the government through local nongovernmental organizations (NGOs), youth organizations, and social work groups as a helping hand to decrease the NCD health care burden on the respective governments and to enhance public health promotion services.

\section{Limitation}

The limitation of this study lies in the sample representativeness restricting to generalize the findings to population of rural areas with low socioeconomic status suffering with NCDs. 


\section{Conclusion}

This survey shows the real-time psychological impact of COVID-19 which has a disastrous effect on the community, such as public, and especially patients with NCDs who are the most vulnerable group. The study findings corroborate with the recent studies conducted on NCDs. The integrated strategic approach to be adopted by creating awareness through mass media campaigns through local NGOs and other social work groups under the government supervision would be an appropriate solution in decreasing the NCD health care burden on our economy which in turn enables safe public health promotion.

\section{Conflict of Interest}

None declared.

\section{Acknowledgment}

The authors thank the participants for their cooperation by taking the survey.

\section{References}

1 Lim MA, Huang I, Yonas E, Vania R, Pranata R. A wave of noncommunicable diseases following the COVID-19 pandemic. Diabetes Metab Syndr 2020;14(05):979-980

2 Rahman ARA. Latest evidence on non-communicable disease management (NCD) during COVID-19 pandemic. IJHHS 2021;5:10
3 World Health Organization. The Impact of the COVID-19 Pandemic on Noncommunicable Disease Resources and Services: Results of a Rapid Assessment. Geneva, Switzerland: World Health Organization; 2020

4 Nethan S, Sinha D, Mehrotra R. Non communicable disease risk factors and their trends in India. Asian Pac J Cancer Prev 2017;18 (07):2005-2010

5 Ahorsu DK, Lin CY, Imani V, Saffari M, Griffiths MD, Pakpour AH. The fear of COVID-19 scale: development and initial validation. Int J Ment Health Addict 2020 (e-pub ahead of print). Doi: 10.1007/ s11469-020-00270-8

6 Andrade EF, Pereira LJ, Oliveira APL, et al. Perceived fear of COVID19 infection according to sex, age and occupational risk using the Brazilian version of the Fear of COVID-19 Scale. Death Stud 2020 (e-pub ahead of print). Doi: 10.1080/07481187.2020.1809786

7 Haktanir A, Seki T, Dilmaç B Adaptation and evaluation of Turkish version of the fear of COVID-19 Scale. Death Stud 2020 (e-pub ahead of print). Doi: 10.1080/07481187.2020.1773026

8 Huarcaya-Victoria J, Elera-Fitzcarrald C, Salvador-Carrillo J, Flores CJ. Psychometric properties of the Spanish version of the fear of COVID-19 scale in Peruvian medical students. Death Stud 2021;0 (00):1-7 10.

9 Thakur JS, Paika R, Singh S, Narain JP. COVID-19 and noncommunicable diseases: Impact and the strategic approaches. Int J Noncommun Dis 2020;5:29-35. Doi: 10.4103/jncd.jncd_35_20

10 BOARD OF GOVERNORS, In supersession of the Medical Council of India. Telemedicine practice guidelines: enabling registered medical practitioners to provide healthcare using telemedicine. Accessed April 16,2021 at: https://www.mohfw.gov.in/pdf/Telemedicine.pdf

11 Merzel C, D'Afflitti J. Reconsidering community-based health promotion: promise, performance, and potential. Am J Public Health 2003;93(04):557-574 